\title{
Logistic Regression Analysis the Risk Factors of Peripherally Inserted Central Catheter Related Blood Stream Infection of Tumor Patients
}

\author{
Jian Song1, Yan Yan², Huang Yan², Chunlin Wang², Jun-e Hu2 ${ }^{2}$ \\ ${ }^{1}$ School of Medicine, Yangtze University, Jing Zhou, China \\ ${ }^{2}$ Department of Oncology, Jing Zhou Central Hospital, Jing Zhou, China \\ Email:654546433@qq.com, 1976416671@qq.com
}

How to cite this paper: Song, J., Yan, Y., Yan, H., Wang, C.L. and Hu, J.-E. (2017) Paper Title. Yangtze Medicine, 1, 169-177. https://doi.org/10.4236/ym.2017.13017

Received: July 17, 2017

Accepted: September 18, 2017

Published: September 21, 2017

Copyright $\odot 2017$ by authors and Scientific Research Publishing Inc. This work is licensed under the Creative Commons Attribution International License (CC BY 4.0).

http://creativecommons.org/licenses/by/4.0/

(c) (†) Open Access

\begin{abstract}
Objective: Our object is to study risk factors of tumor patients' PICC catheterrelated blood stream infection. Method: a retrospective analysis of data of 586 PICC catheterized patients was implemented, a univariate analysis of general data and catheterizing data of tumor patients was then carried out, and data of single factors with statistical significance were incorporated into multi-factor Logistic regression model for analysis. Results: PICC catheter-related blood stream infection occurred to 16 patients, and occurrence rate was $2.73 \%$. Multifactor Logistic regression analysis results showed that number of puncturing times, positioning method and maintenance frequency were risk factors for tumor patients' peripherally inserted central catheter catheter-related blood stream infection, and odds risk values were respectively 8.762, 9.253 and 10.324. Conclusion: for tumor patients implanted with peripherally inserted central catheters, using ECG positioning during strict sterile operation and catheterizing process to avoid repeated puncturing and increasing maintenance frequency could effectively reduce occurrence of PICC catheter-related blood stream infection.
\end{abstract}

\section{Keywords}

PICC Related Blood Stream Infection, Logistic Regression Analysis, Risk Factor

\section{Introduction}

By virtue of advantages like once implantation with long-term utilization, few complications, possible bedside operation, reduction and prevention of risks caused by drug extravasation, etc., peripherally inserted central catheter (PICC) cathete- 
rization has been clinically applied within a large scope [1]. With extensive application of PICC catheter, PICC catheter-related blood stream infection has been gradually recognized. PICC catheter-related blood stream infection (PICC-CRBSI) refers to that patients, who carry intravascular catheters or whose intravascular catheters are removed within 48 hours, suffer from bacteremia or fungemia accompanied by infectious manifestations like fever $\left(>38^{\circ} \mathrm{C}\right)$ and shivering and there is no any other infection source except intravascular catheter [2]. PICC-CRBSI, an important complication of long-term retention of vein catheterization, will lengthen length of stay (LOS) of patients and cause waste of medical resources in less severe case once it happens, and more seriously, it will cause patient death and medical dispute. Research shows that CRBSI occurrence rate of PICC patients is $12.7 \%-32.7 \%$, infection rates of Gram-positive bacteria and Gram-negative bacteria are respectively $38.8 \%-64.4 \%$ and $35.56 \%-41.2 \%$, fungal infection rate is $0 \%-20.0 \%$ and average death rate among infected patients is $12 \%-25 \%$ [3] [4]. Therefore, it's of great importance to actively explore into risk factors causing PICC-CRBSI. A retrospective analysis of 586 patients carrying PICC catheters was implemented in this paper and occurrence rate of PICC-CRBSI to tumor patients and its relevant risk factors were discussed so as to provide basis for clinical prevention of tumor patients' PICC catheter-related blood stream infection.

\section{Data and Method}

\subsection{Research Object}

PICC-catheterized patients in central venous indwelling catheter registration database in one of the level-three class-A hospital from February in 2016 to February in 2017. During this time, a total of 756 patients were applied with a PICC catheterization. For the research purposes, we set up inclusion and exclusion criteria, and inclusion criteria were: 1) more than 18 years old; 2) diagnosed as malignant tumor for the first time through histopathology; 3) implanted with trivalve single-cavity high voltage-resistant PICC catheters by clinical nurse specialists; 4) PICC catheterizing time lasted at least 3 months. Exclusion criteria: 1) patients with preexistence of catheter-related thrombosis, deep venous thrombosis, catheter-related blood stream infection or lymphatic backflow obstruction; 2) Those who don't have obtain information such as: death, abandon treatment and contact lost were deleted. Diagnostic criteria of PICC catheter-related blood stream infection were subjected to Prevention and Treatment Guidelines of Intravascular Catheter-Related Infection (2007) [5]. Because this study is a retrospective study, so no patients required to sign informed consent. Under the approval of the Hospital Academic Ethics Committee authors found out the medical clinical records, finally 586 patients meeting the criteria were selected, where 16 ones suffered from PICC catheter-related blood stream infection, the occurrence rate was $2.73 \%$. However this occurrence rate was lower than the previous reported $12 \%$ $25 \%$ of the incidence [3] [4]. 


\subsection{Methodology}

\subsubsection{Observational Indexes General Data}

(Gender, age, occupation, degree of education, pathological type, clinical staging, complications, operation history and antibacterial agent application) and catheterizing data (number of puncturing times, positioning method, punctured limbs, catheterizing time, maintenance frequency and maintenance plane) of tumor patients.

\subsubsection{Data Collection Method}

Through unified training, 2 postgraduates and PICCC clinical nurse specialists looked up and recorded general data and catheterizing data of research objects who met criteria according to incorporation \& exclusion criteria and medical record number.

\subsubsection{Statistical Method}

SPSS 19.0 software was used for statistical analysis, measured data were expressed by $\bar{X} \pm s$, enumeration data were expressed by percentages, and comparison of means of two samples was implemented through $\mathrm{t}$ test. $\chi^{2}$ test was used for comparison of enumeration data. Logistic regression analysis of dichotomous outcome variables was used for multi-factor analysis.

\section{Results}

\subsection{Occurrence of PICC Catheter-Related Blood Stream Infection}

16 cases among 586 patients suffered from PICC catheter-related blood stream infection, therefore occurrence rate was $2.73 \%$ : which was lower than what's reported in past researches [2] [3], and this might be related to the fact that only 16 patients infected with typical clinical manifestations like fever $\left(>38^{\circ} \mathrm{C}\right)$ and shivering were observed in this study but screening of patients without any symptom was not implemented.

\subsection{Univariate Analysis of Influence on Occurrence of PICC Catheter-Related Blood Stream Infection (Table 1)}

Univariate analysis results showed that the differences of PICC catheter-related blood stream infection from pathological type, complications, number of puncturing times, positioning method, maintenance frequency and maintenance place had statistical significance $(\mathrm{P}<0.05)$, but differences of ICC catheter-related blood stream infection from gender, age, occupation, degree of education, clinical staging, operation history, use of antibacterial agents, punctured limbs and catheterizing time didn't have statistical significance $(P>0.05)$.

\subsection{Multi-Factor Analysis of Influence on Occurrence of PICC Catheter-Related Blood Stream Infection (Table 2 and Table 3)}

Whether PICC-CRBSI happened was taken as a dependent variable (dependent variable: patients without occurrence of PICC catheter-related blood stream infection 
Table 1. Univariate analysis of occurrence of tumor patients' PICC catheter-related blood stream infection (cases, percentage (\%)).

\begin{tabular}{|c|c|c|c|c|}
\hline Item & $\begin{array}{l}\text { Number of patients } \\
\text { without occurrence of } \\
\text { the infection }\end{array}$ & $\begin{array}{l}\text { Number of patients } \\
\text { with occurrence of } \\
\text { the infection }\end{array}$ & $\begin{array}{l}\text { Statistical } \\
\text { magnitude }\end{array}$ & $\mathrm{P}$ value \\
\hline Gender & & & 0.871 & 0.351 \\
\hline Male & $384(67.37)$ & $9(56.25)$ & & \\
\hline Female & $186(32.63)$ & 7 (43.75) & & \\
\hline Age & $61.26 \pm 9.87$ & $64.76 \pm 9.87$ & 1.091 & 0.463 \\
\hline Occupation & & & 0.643 & 0.587 \\
\hline Worker & $112(19.65)$ & $5(31.25)$ & & \\
\hline Peasant & $187(32.81)$ & $4(25.00)$ & & \\
\hline Teacher & $117(20.53)$ & $2(12.50)$ & & \\
\hline Others & $154(27.02)$ & $5(31.25)$ & & \\
\hline Degree of education & & & 0.448 & 0.503 \\
\hline Junior high school and below & $367(64.39)$ & $9(56.25)$ & & \\
\hline Senior high school land above & $203(35.61)$ & $7(43.75)$ & & \\
\hline \multicolumn{5}{|l|}{ Pathological type } \\
\hline Leukemia & $112(19.65)$ & $12(75.00)$ & 25.359 & $<0.000^{*}$ \\
\hline Non-leukemia & $458(80.35)$ & $4(25.00)$ & & \\
\hline Clinical staging & & & 1.952 & 0.162 \\
\hline I-II & $279(48.95)$ & $5(31.25)$ & & \\
\hline III-IV & $291(51.05)$ & $11(68.75)$ & & \\
\hline Complications & & & 14.103 & $<0.000^{*}$ \\
\hline YES & $95(16.67)$ & $9(56.25)$ & & \\
\hline NO & $475(83.33)$ & $7(43.75)$ & & \\
\hline Operation history & & & 0.143 & 0.202 \\
\hline YES & $251(44.04)$ & $10(62.50)$ & & \\
\hline NO & $319(55.96)$ & $6(37.50)$ & & \\
\hline Use of antibacterial agents & & & 0.249 & 0.313 \\
\hline
\end{tabular}




\section{Continued}

\begin{tabular}{|c|c|c|c|c|}
\hline YES & $309(54.21)$ & $11(68.75)$ & & \\
\hline NO & $261(45.79)$ & $5(31.25)$ & & \\
\hline $\begin{array}{l}\text { Number of puncturing times } \\
\text { (times) }\end{array}$ & & & 20.955 & $<0.000^{*}$ \\
\hline 1 & $421(73.86)$ & $3(18.75)$ & & \\
\hline$>1$ & $149(26.14)$ & $13(81.25)$ & & \\
\hline Positioning method & & & 30.027 & $<0.000^{\star}$ \\
\hline Chest radiography & $108(18.95)$ & $12(75.00)$ & & \\
\hline ECG positioning & $462(81.05)$ & $4(25.00)$ & & \\
\hline Punctured limbs & & & 0.662 & 0.457 \\
\hline Left forearm & $297(52.11)$ & $10(62.50)$ & & \\
\hline Right forearm & $273(47.89)$ & $6(37.50)$ & & \\
\hline Catheterizing time (months) & & & 0.240 & 0.624 \\
\hline$\leq 6$ & $130(22.81)$ & $5(31.25)$ & & \\
\hline$>6$ & $440(77.19)$ & $11(68.75)$ & & \\
\hline $\begin{array}{l}\text { Maintenance frequency } \\
\text { (times-week) }\end{array}$ & & & 38.493 & $<0.000^{\star}$ \\
\hline 0 & $96(16.84)$ & $13(81.25)$ & & \\
\hline$\geq 1$ & $474(83.16)$ & $3(18.75)$ & & \\
\hline Maintenance place & & & 13.177 & $<0.000^{\star}$ \\
\hline In the hospital & $389(68.25)$ & $4(25.00)$ & & \\
\hline Out of the hospital & $181(31.75)$ & $12(75.00)$ & & \\
\hline
\end{tabular}

Note: ${ }^{\star}$ represents $\mathrm{P}<0.05$ representing that the difference has statistical significance.

Table 2. Assignment of independent variables.

\begin{tabular}{lc}
\hline Independent variable & Assignment method \\
\hline Pathological type & $0=$ non-leukemia; 1 = leukemia \\
Complication & $0=$ NO; 1 = YES \\
Number of puncturing times & $0=1$ times; $1 \geq 1$ times \\
Positioning method & $0=1$ (times/week); $1=0$ (times/week) \\
Maintenance frequency & $0=$ ECG positioning; $1=$ chest radiography positioning \\
Maintenance place & $0=$ in-hospital maintenance; $1=$ out-of-hospital maintenance
\end{tabular}


Table 3. Multi-factor logistic regression of tumor patients concurrent with PICC catheter-related blood stream infection.

\begin{tabular}{cccccc}
\hline Independent variable & $\mathrm{B}$ & $\mathrm{SE}$ & $\mathrm{P}$ & $\mathrm{OR}$ & $95 \% \mathrm{CI}$ \\
\hline Constant term & 13.42 & 4.652 & $<0.001$ & $<0.001$ & $4.652-23.632$ \\
Number of puncturing times & 3.782 & 0.746 & $<0.001$ & 8.762 & $4.053-23.685$ \\
$\quad$ Positioning method & 6.322 & 0.674 & $<0.001$ & 9.253 & $5.693-32.157$ \\
Maintenance frequency & 5.736 & 0.324 & 0.003 & 10.324 & $2.329-24.956$ \\
\hline
\end{tabular}

$=0$, and patients with occurrence of PICC catheter-related blood stream infection $=1)$ and variables with statistical significance $(\mathrm{P}<0.05)$ in univariate analysis were incorporated into Logistic regression mode, and results showed that number of puncturing times, positioning method and maintenance frequency were risk factors of tumor patients with concurrence of PICC catheter-related blood stream infection. Odds risk values of multiple times of puncturing, chest radiography positioning and low maintenance frequency ( $\leq 1$ times/week) were respectively $8.762,9.253$ and 10.324 .

\section{Discussion}

\subsection{Occurrence of PICC Catheter-Related Blood Stream Infection to Tumor Patients}

The study results showed that occurrence rate of symptomatic PICC-CRBSI was $2.73 \%$, which was similar to what's reported by many of the other scholars. 16 patients with occurrence of PICC-CRDSI in this study experienced obvious clinical symptoms, but PICC-CRBSI without delete typical clinical symptoms might exist in practical work, The occurrence rate of PICC-CRBSI might be far higher than existing reports, which might be related to the fact that high fever occurring in chemoradiotherapy of tumor patients was usually deemed as tumor-related fever without consideration of PICC-CRBSI. This indicated that medical personnel should blindly use antibiotics when faced with high fever of tumor patients carrying catheters not simply considering it as tumor-related fever, but instead, comprehensively considering whether patients had risks of PICC-CRBSI and make etiological quantitative examination when necessary. Antibiotics should be reasonably used according to etiological examination results or optimal intervention measures should be selected according to standard treatment process of PICC-CRBSI to ensure patient safety.

\subsection{Repeated Puncturing Is a Risk Factor of PICC-CRBSI Occurrence}

The study results indicated that repeated puncturing was a risk factor of PICC-CRBSI occurrence with similar finding to past studies, all of which believed that the more times of puncturing during catheterizing process, the higher the risks of inducing PICC-CRBSI would be [6] [7]. The risk of PICC-CRBSI occurrence when 
number of puncturing times was greater than 1 was 8.762 times of 1 successful puncturing, possibly because repeated puncturing, difficult catheterizing and catheter misplacement during catheterizing process would result in damage of blood vessel wall and subcutaneous tissues, lengthened tissue repair time and increased possibility for bacterial invasion to cause infection, and moreover, catheter may be polluted before entering human body due to lengthened operation time and too long exposure of sterile articles. Therefore, administrative department should enhance qualification access system of PICC catheterizing nurses and ensure that PICC specialized nurses had excellent puncturing technology. Meanwhile, "blind puncturing" should be avoided during catheterizing process, catheterizing success rate was improved by $98 \%$ with B-ultrasound guidance combining improved Seldinger technique [8]. After three times of unsuccessful puncturing, puncturing might not be implemented, or otherwise complications would present fold increase [9].

\subsection{X-Ray Chest Radiograph Positioning Is a Risk Factor of PICC-CRBSI Occurrence}

Study results found that PICC-CRBSI risk of X-ray chest radiography positioning was 9.253 times of ECG positioning. To reach the effect of once implantation with long-term use, the position of the head of PICC is of vital importance. Nowadays most hospitals in China still take X-ray chest radiograph positioning as the only "gold standard" but its disadvantages have gradually been highlighted with disciplinary progress, The following $\mathrm{X}$-ray chest radiograph and may be used only after catheterization. If PICC catheter head has malposition, then it's necessary to readjust the catheter or re-implant the catheter after removal. During the process, the catheter exposed in the air has been polluted so that it's difficult to achieve strict sterilization during catheter debugging process, consequently bacteria adhered onto the catheter will possibly cause bacterial infection [10], and bacterial infection is the most important original inducing factor of PICC-CRBSI. Hence, in future work, ECG positioning method should be widely applied to positioning of PICC catheter head, and advantages of ECG which can timely observe catheter position with integrated catheterizing and positioning should be taken fully.

\subsection{Irregular Maintenance Is a Risk Factor of PICC-CRBSI Occurrence}

Risk of PICC-CRBSI occurrence due to irregular maintenance in this study was 10.324 times of regular maintenance. As a new venous treatment means, PICC has been widely carried out in superior hospitals and have penetrated into primary hospitals gradually. At present, most county-level hospitals and all healthy clinics in towns lack personnel mastering PICC maintenance technique due to disadvantages in aspects of hardware and personnel. Consequently, regular maintenance can't be achieved during therapeutic intermission of many patients so 
that loose herbal application, bacterial reproduction and infection are then caused. Most research objects selected in this study came from rural areas, great difficulties existed in maintenance per week because of factors like their economic status, traffic condition and scattered regional distribution. Many patients chose self-care at home, which not achieve sterilization and increased infection risk [11] [12] [13]. Irregular maintenance namely maintenance frequency which was lower than 1 time/week was a risk factor of PICC-CRBSI occurrence. Therefore, we should establish PICC maintenance network centered on regional medical treatment and covering peripheral counties and cities, strengthen training of medical care personnel at basic level, so as to improve maintenance level of nursing staff at basic level, patients compliance with PICC maintenance and reduce occurrence rate of PICC infection due to medical care personnel during treatment intermission.

\section{Limitation}

Only a retrospective analysis of 586 PICC catheterized patients was made in this study. Logistic regression model was used to analyze risk factors of patients with PICC-CRBSI, but in practical work, many risk factors exist before, in the middle of and after catheterization. No final conclusion has been formed for many potential risk factors and relative risk degree of each risk factor has not been further verified. Therefore, large-sample case-control study should be carried out in future study to accurately explore into risk factors of PICC-CRBSI so as to realize early-stage recognition of risk factors and judge possibility of CRBSI occurrence. Intervention should be made in key link to ensure patient safety.

\section{References}

[1] Shi, Y., Zheng, Y.P., Li, Y., et al. (2017) Application of Simultaneous Single-Hand Double-Cavity Catheter Locking in Prevention of PICC Catheter Plugging. Chinese Journal of Nursing Science, 52, 621-623.

[2] Li, R.Q., Jiang, D.Q. and Lv, Y.J. (2016) Observation and Nursing of Different Pathogenic Bacteria-Induced PICC Catheter-Related Blood Stream Infection. Chinese Journal of Nursing Science, 51, 1368-1370.

[3] Xu, X.F., Zhao, X.H. and Wu, L.H. (2015) Comparative Study of Application of Different Infusion Connectors to CVC-Related Blood Stream Infection. Chinese Journal of Nosocomial Infection, 25, 2025-2027.

[4] Zheng, X., Liu, W., Liu, X.M., et al. (2012) Analysis of CVC-Related Pathogenic Bacterial Distribution of 520 Tumor Patients Peripherally Implanted with Catheters. Modern Diagnosis and Treatment, 23, 1554-1555.

[5] Fang, Q. (2008) Prevention and Treatment Guidelines for Intravascular Catheter-Related Infection. Chinese Journal of Practical Surgery, 17, 597-605.

[6] Gao, A.Y. (2012) Cause Analysis and Intervention Measures of Vein Catheterization-Related Blood Stream Infection. Chinese Journal of Nosocomial Infection, 22, 3758-3759.

[7] Jiang, W. and Zeng, D.F. (2015) Research Progress of Risk Factors and Preventive Measures of PICC-Related Blood Infection. Chinese Nursing Management, 15, 218-221. 
[8] Johnson, M.A., Mckenzie, L., Tussey, S., et al. (2009) Portable Ultrasound: A Cost-Effective Process Improvement Tool for PICC Placement. Nursing Management, 40, 47-50. https://doi.org/10.1097/01.NUMA.0000343984.23505.37

[9] Song, P. and Li, Z.D. (1999) Enlightenment of CVC Complications. Journal of Practical Nursing, 15, 7-8.

[10] Yuan, L., Li, R.M., Li, S.P., et al. (2015) Effect Comparison of Two Methods on Trivalve PICC-Guided Intracardiac Electrocardiogram. Chinese Journal of Nursing Science, 50, 1055-1059.

[11] Luo, H., Ren, D.Q., Tan, J., et al. (2013) Construction and Implementation of Hospital-Community-Family Integrated PICC Maintenance Network Pattern. Chinese Journal of Nursing Science, 28, 16-18.

[12] Lin, N. and Wu, A.Z. (2015) Prevalence Survey of Website Maintenance of Discharged Patients Carrying Catheters. Modern Nurse Periodical (Every Ten Days), No. 6, 88-89.

[13] Wu, Y., Hu, Q.X., Hu, S.R., et al. (2015) Construction of PICC Maintenance Network and Nursing Practice. Sichuan Medical Journal, 36, 1183-1187.

\section{Submit or recommend next manuscript to SCIRP and we will provide best} service for you:

Accepting pre-submission inquiries through Email, Facebook, LinkedIn, Twitter, etc. A wide selection of journals (inclusive of 9 subjects, more than 200 journals)

Providing 24-hour high-quality service

User-friendly online submission system

Fair and swift peer-review system

Efficient typesetting and proofreading procedure

Display of the result of downloads and visits, as well as the number of cited articles

Maximum dissemination of your research work

Submit your manuscript at: http://papersubmission.scirp.org/

Or contact ym@scirp.org 